\title{
Da liberalização cega dos anos 90 à construção estratégica do desenvolvimento
}

\author{
GLAUCO ARBIX
}

RESUMO: Este texto foi apresentado na aula inaugural do curso de Ciências Sociais da USP, realizada no dia 6 de março de 2002. A economia global vem sendo sacudida por alterações profundas que vêm alterando os métodos, a estrutura produtiva de bens e serviços, a política e as instituições em todos os cantos do planeta. Essas mudanças estão sendo mais sentidas nos países que apresentam em sua história uma presença marcante do Estado sobre as economias e a vida social. Na América Latina, essas mudanças orientaram a implantação de um novo modelo de política econômica, como forma de superar a inflação crescente, os déficts comerciais, o fardo da dívida externa, a ineficiência e a falta de competitividade internacional que, supostamente, haviam se configurado como fruto das tradicionais políticas desenvolvimentistas. No entanto, esse novo modelo opera com uma interpretação tortuosa da história dos países em desenvolvimento, jogando no esquecimento ou tornando incompreensível que países como Brasil, Argentina e México, ao lado de outros asiáticos, cresceram após a II Guerra Mundial mais rapidamente que Estados Unidos, Inglaterra, Alemanha, França e Canadá. A elaboração de estratégias de desenvolvimento, incluindo a qualidade da industrialização desejada, da tecnologia, das instituições e da política, continua sendo o principal desafio a ser vencido pelos países atrasados.

m Varsóvia, no final de fevereiro, o presidente Fernando Henrique Cardoso esboçou uma crítica ao Fórum Econômico Mundial, de Davos, e ao seu contraponto, o Fórum Social Mundial de Porto Alegre. "Os títulos de ambas as reuniões são engano-
PALAVRAS-CHAVE:

América Latina, países em desenvolvimento, tecnologia, livre comércio, estratégias de desenvolvimento.

Professor do Departamento de Sociologia da FFLCH-USP 
sos", disse o presidente" pois “...há uma certa ironia no fato de que as palavras 'econômico e social' estejam sendo usadas como se existisse uma escolha a ser feita"1 . Na visão do presidente, após a queda do muro de Berlim, em 1989, o discurso de cunho somente "social" ou "econômico" teria se tornado obsoleto.

Fernando Henrique, apesar de ter incorporado a queda do muro de Berlim em suas análises, não foi muito preciso em seus comentários. Principalmente porque uma das fraturas mais importantes que vem marcando a economia contemporânea reside no fosso crescente que separa a economia da sociedade. No final do século XX, os países que mais trocaram intimidades com as políticas de perfil liberal, como o Brasil, estamparam essa marca de modo flagrante, levando as sociedades a se submeterem aos desígnios da economia e não o inverso.

Esse é o estigma fundamental que carrega a produção dominante de conhecimento, métodos e técnicas de pesquisa da economia contemporânea. Desde que abandonou o selo "economia política" essa tendência prevaleceu, atenuada em alguns momentos de despertar democrático, em que as políticas públicas foram marcadas pela busca do pleno emprego e pela necessidade de construção de mecanismos de proteção social. Na década de 90, quando essa distância mais se fez sentir pelo mundo afora, a preocupação saudável com o bem estar de povos e populações revelou uma triste realidade em meio à parafernália de novos métodos e sofisticados controles dos planejadores econômicos. A queda do Muro de Berlim e a emergência da nova onda que invadiu o circuito da economia ajudou a abalar doutrinas e pressupostos ideológicos que haviam informado o mundo da política dos países atrasados em sua tentativa de proteger e estimular suas economias e, dessa forma, alcançar o crescimento. No início, o despertar liberal parecia restrito aos Estados Unidos e à Inglaterra, sob o domínio de Reagan (1980/88) e Thatcher (1979/90), mas suas decisões estratégicas acabaram por expandir-se para todo o planeta, contagiando governos, agências estatais, o mundo do big-business e as universidades.

No entanto, resultados decepcionantes contrastam com as virtudes anunciadas pela ofensiva liberalizante. A esse respeito, vale a pena relembrar que o fato econômico mais espetacular desde o pós II guerra reside na diferença e contraste da renda que separa - e que vem aumentando - as nações ricas das pobres e entre pobres e ricos dentro de uma mesma região ou país. A renda média do país mais pobre do mundo (Serra Leoa) é quase cem vezes menor do que a do mais rico (Luxemburgo), sendo que mais de $70 \%$ da população mundial vivem em países com uma renda média de cerca de 1/10 da dos Estados Unidos. Se atentarmos para o fato de que antes da revolução industrial o ponto de

${ }^{1}$ Folha de S. Paulo, 26/02/2002, p. A8. partida de praticamente todos os países era muito semelhante, as fortes disparidades atuais obrigam-nos a refletir sobre as razões dessa 
diversificada - e trágica - evolução da renda. Para tanto, é fundamental capturar as oscilações das diretrizes econômicas que sustentaram as inflexões nas políticas desenvolvidas pelos países em quase todo o mundo na década de 90.

Nesse sentido, é possível realçar que um movimento pendular ${ }^{2}$ pareceu tomar conta da economia, sugerindo um novo ciclo teórico e prático predominante, com profundo impacto nas economias subdesenvolvidas. Foi quando as práticas de liberalização adotadas pelos mais diferentes governos passaram a expressar, de fato, a força avassaladora das grandes economias, que penetraram por todos os poros o "resto" do mundo. A fala predominante das grandes potências mostrou-se rapidamente monocórdica, pragmática, arrogante e firmou-se graças à autoridade de instituições internacionais, como o FMI e o Banco Mundial, que procuraram associar qualquer desempenho econômico significativo à existência de mercados competitivos, direitos contratuais e de propriedade protegidos, estabilidade macroeconômica e serviços públicos eficientes. Com as pressões, as sociedades foram sendo gradativamente reduzidas à macroeconomia, aumentando o desconforto dos planejadores dos países em desenvolvimento e constrangendo toda tentativa de regular, disciplinar e orientar os mercados.

$\mathrm{Na}$ raiz desse fenômeno, um encolhimento brutal da política, do mundo da produção e da organização das sociedades. O Estado, agora vilão, foi sendo drenado de seu poder estruturante, o que ajuda a construir instituições e novas relações sociais, o que facilita a cooperação e a pactação social. Os governantes, muito dos quais esclarecidos, aceitaram esse novo enquadramento da sociedade como se fosse uma nova inteligência científica. Uma estranha troca, pois cada parcela de poder de Estado perdido - ou alienado, ou delegado - acabou deixando em suas mãos, como disse o filósofo, quase nada "a não ser um fictício poder de decisão" (Habermas, 1971, p. 64).

Os sinais emitidos por essa nova inflexão do pêndulo tornaramse cada vez mais contundentes. Analisando o suposto rigor dessa economia científica, Bourdieu afirmou que "a nova vulgata planetária se apóia em uma série de oposições e equivalências, que se sustentam mutuamente, e das quais dependem as transformações contemporâneas das sociedades avançadas: descompromisso econômico do Estado e fortalecimento de suas instituições policiais e penais; desregulamentação dos fluxos financeiros e flexibilização do mercado de trabalho; redução da proteção social e celebração moral das responsabilidades individuais" (Bourdieu \& Wacquant, 2000, p. 6-7). Em outras palavras, uma nova mitologia político-conceitual começou a tomar forma. Ao se perguntar pelo mercado (entendido como o reino da flexibilidade, diversidade, autenticidade, da democracia e do futuro), encontrava respostas no Estado, definido por sua rigidez, obsolescência, uniformidade, artificialidade e autocracia. E

${ }^{2}$ A expressão foi tomada de empréstimo de Taylor, 1994, p. 59. 
vice-versa.

A força analítica dessa simplificação não era grande e ela só ganhou relevância com a inestimável ajuda de um forte discurso da persuasão política, geralmente efetivado por personagens até então alheios aos pressupostos liberais, e com a desagregação política das economias que tentaram o socialismo como alternativa ao capitalismo. Com esses ingredientes de destaque nos anos 90, a moldagem do protótipo vencedor ficaria nas mãos dos países mais avançados, dos mais ricos, financeirizados e tecnologizados, que procuraram reconfigurar o capitalismo como the only game in town.

Mesmo assim, foram privilegiados apenas alguns tipos de capitalismo. Experiências recentes como a dos tigres asiáticos, ou anteriores, como as de inspiração na CEPAL (com destaque para o Brasil do pósguerra), exigiram dos economistas do Banco Mundial e do FMI uma ginástica conceitual para explicar as razões de seu crescimento acelerado em condições bem distantes da vulgata liberal. Ou seja, países atrasados, tradicionalmente marcados para não crescer, haviam crescido. Outros, sob olhares de descrédito, fugiam das regras predominantes e alcançavam êxitos parciais exatamente ali onde só fracassos e ineficiências poderiam existir.

As estratégias disseminadas entre os asiáticos, por exemplo, guardaram distância tanto das prescrições anglo-saxãs como das propostas de perfil socialista, mesmo das identificadas com a chamada terceira via. O interessante nesse processo é que quanto mais os economistas enfatizaram suas atribuições científicas, mais identificaram a ciência apenas a alguns modelos de capitalismo, basicamente aqueles em que as sociedades mais subordinaram seu destino à condução da economia. Essa é a base para um discurso recorrente, principalmente em tempos eleitorais, que tenta difundir a idéia de que "chegou a hora do social". Neste caso, 'social' é apresentado como rima oculta de 'ocasional'.

Nec spe nec metu - sem esperança mas também sem medo diria com Ezra Pound. A esperança adquire outros contornos com o passar do tempo. Sem medo porque é preciso afastar-se do clima eleitoral para exercer a única arma de que a universidade dispõe, a razão crítica. Diga-se de passagem, esse é um dos motivos pelos quais a reflexão sobre o desenvolvimento - ou sobre o não desenvolvimento dos últimos 20 anos - tende a assumir um lugar importante no espaço universitário. Este ano teremos a III versão do Seminário Internacional da USP sobre "Novos

${ }^{3}$ Uma iniciativa inédita e conjunta do Depto. de Sociologia da FFLCH, da FEA e da Escola Politécnica da USP. Homepage: www.vanzolini.org.br/ seminariousp Paradigmas de Desenvolvimento", 3 cuja preocupação essencial vem sendo a busca de alternativas para o nosso crescimento. Isso porque os anunciados movimentos de convergência e harmonização da economia, da tecnologia e da produtividade, para além das futilidades analíticas geradas no embalo da globalização, foram fragorosamente desautorizados pela realidade dos movimentos de divergência que se acentuaram nos anos 90 
e que estão longe de se esgotar.

Ou seja, os hiatos que realmente separam os países não serão superados numa espécie de movimento inelutável, próprio da economia mundial, que tenderia sempre a puxar os países retardatários a um patamar razoavelmente mais alto. Pode parecer ingênuo, mas diante da intensificação da pressão competitiva, muitos países, como o Brasil, acabaram por abandonar ou deslocar suas prioridades sociais, aumentando seus contrastes, corroendo as bases de sua solidariedade e perdendo, com isso, sua linha de futuro. Longe de aproximar-se dos mais avançados, distanciaram-se, como se cumprissem a sina de permanecerem apenas como esboços de países, numa espécie de subdesenvolvimento sustentável.

Na batalha cotidiana, a complacência diante das novas exigências de inserção nos mercados mundiais tem levado os governos a questionar e a subordinar os projetos sociais aos desígnios da economia. É o que empurra governantes a formular suas políticas de emprego, de redistribuição e de renda quase que unicamente voltadas para o estímulo ao crescimento dos meios de produção privados e do capital humano individual, agora apresentados como ativos de interesse coletivo. Exatamente por isso, os governos têm sido incentivados pelos organismos financiadores internacionais a descarregar seus investimentos no início dos processos de capacitação, o que supostamente funcionaria como meio equalizador das oportunidades individuais diante do novo mercado. O resultado é que essa orientação dos investimentos torna as políticas e programas estratégicos de redistribuição praticamente desnecessários, pois grande parte de suas responsabilidades tende a ser transferida para o indivíduo e cidadão ou, no máximo, deixados ao sabor da benemerência empresarial. Quando esse tipo de desamparo surge no horizonte, sempre é útil recorrer a um autor como Polanyi, para quem as sociedades resistem à sua pulverização e suas instituições, quando ameaçadas, buscam proteção e sobrevivência.

Nesse sentido, apesar de seu caráter descontínuo e fragmentário, as resistências à globalização que vêm aflorando em quase todo o mundo podem ser entendidas como uma reação à extrema mercantilização da vida provocada pela dieta liberal. Ainda que difusa e, muitas vezes, inconsistente, essa reação convida-nos a retomar questões que marcaram o nascimento da sociologia, como a idéia de sociedade como proteção. Quais caminhos poderiam ser trilhados nessa direção?

Antes de mais nada, há uma série de novos estudos (cf. Rodriguez e Rodrik, 2000; Chang, 2001, Ocampo, 2001; Wade, 1990 ) que procuram mostrar que os episódios mais duradouros no que se refere ao crescimento fazem-nos olhar para a China e a Índia, para a Ásia e, no período imediatamente posterior à II guerra, para o Brasil e o México. Esse olhar, logo de início, orienta nossa análise para a busca dos países que atingiram um alto grau de crescimento sem que houvesse qualquer coincidência com fases de liberalização econômica. Esse é um argumento poderoso, que o governo brasileiro 
e, acredito, também a pesquisa universitária relegaram a empoeiradas gavetas em anos recentes. E por quê?

A febre dos anos 90 apontou o livre comércio como premissa para o desenvolvimento, ao lado da busca de uma nova inserção na economia mundial. Importante? Claro. Mas, em primeiro lugar, é preciso perguntar: qual inserção? Nos séculos XVII, XVIII e XIX, por exemplo, tivemos um bom relacionamento com a economia mundial, mas através do tráfico de escravos. Esse tipo de inserção não soa, contudo, exatamente como algo desejável. Em segundo lugar, além do tipo, somos levados a perguntar pelo poder envolvido. Ou seja: quem, qual governo, qual agência seriam capazes de decidir o modo como se dá a inserção de um país? Inserção diz respeito a relações que os países contraem com o resto do mundo, com os mercados, sendo que um instrumento privilegiado diz respeito às exportações. Em nosso caso, há muitos produtos que poderiam ser exportados se contassem com políticas adequadas. Mas seria inócuo se o governo decretasse um incremento das exportações ou, numa figuração mais destemperada, se o presidente apenas conclamasse: exportar ou morrer!

Essas são questões importantes que nem sempre têm merecido a devida atenção dos decision makers. Ou seja, sem capacitação e preparo preliminar, sem que as políticas estejam integradas a projetos de envergadura, a inserção será sempre vista como mais um tiro n'água. Como o foram todos os planos de exportação nos primeiros cinco anos do governo Fernando Henrique, quando o real sobrevalorizado impedia o desenvolvimento de nossa incipiente capacidade exportadora. O discurso, neste caso, nem forças tinha para dissimular.

Se cavocarmos ainda mais em busca das raízes das escolhas recentes, vamos encontrar, no longo prazo, balanços mal delineados sobre a experiência desenvolvimentista e, no curto prazo, análises mal digeridas dos anos 80, a chamada década perdida, ambas interligadas.

Creditando a estagnação dos anos 80 às políticas protecionistas configuradas desde o pós-guerra, os novos governantes da década de 90 foram abandonando as políticas desenvolvimentistas e de substituição de importações, tentando se livrar da state-led tradition que marcou o continente latino-americano por décadas, e que começou a ser substituída por um novo paradigma de política econômica, de forte viés privatizante e pró-mercado, tanto no nível interno quanto no externo. Coerentes com esse modelo, desde 1998, 103 países ofereceram condições especiais para atrair corporações estrangeiras (cf. Unctad, 2000). Os novos padrões de atração utilizados incluíram isenções fiscais, quebra de barreiras alfandegárias, diminuição de taxas e impostos de importação, empréstimos subsidiados e outros subsídios indiretos.

Mudanças fundamentais ocorreram nos sistemas político-ideológicos e no modus operandi das economias, com impacto profundo na maneira como os países buscam atingir seus alvos e defender seus interesses. Desse ponto de vista, não há como negar que os governos tiveram êxito em sua empreitada, pois os investimentos externos estão desempenhando papel inédito na história das economias da América Latina. 


\section{Gráfico 1}

Fluxo de Investimento Direto Externo IDE - 1990-2000

(Bilhões de dólares)

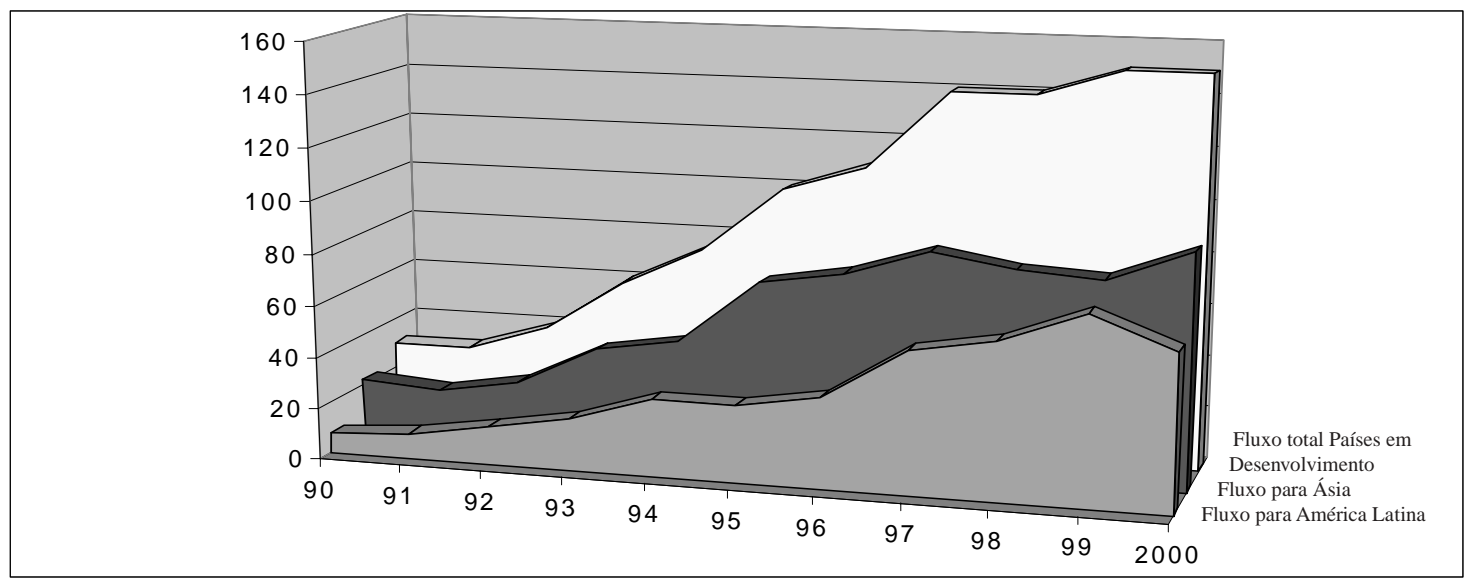

Fonte: Cepal, 1999; UNCTAD, 2000.

Tabela 1

Países da América Latina - Fluxo de Investimento Direto Externo IDE - 1990-2000 (Milhões de dólares)

$\begin{array}{lllllll}1990-1994 * & 1995 & 1996 & 1997 & 1998 & 1999 & 2000 * *\end{array}$

\begin{tabular}{|c|c|c|c|c|c|c|c|}
\hline Argentina & 2982 & 5315 & 6522 & 8755 & 6670 & 23579 & 11957 \\
\hline Bolívia & 85 & 393 & 474 & 731 & 957 & 1016 & 695 \\
\hline Brasil & 1703 & 4859 & 11200 & 19650 & 31913 & 32659 & 30250 \\
\hline Chile & 1207 & 2957 & 4634 & 5219 & 4638 & 9221 & 3676 \\
\hline Colômbia & 818 & 968 & 3113 & 5638 & 2961 & 1140 & 1340 \\
\hline Equador & 293 & 470 & 491 & 625 & 814 & 690 & 740 \\
\hline México & 5430 & 9526 & 9186 & 12831 & 11312 & 11786 & 12950 \\
\hline Paraguai & 99 & 103 & 136 & 233 & 196 & 95 & 100 \\
\hline Peru & 796 & 2056 & 3225 & 1781 & 1905 & 1969 & 1193 \\
\hline Uruguai & $\ldots$ & 157 & 137 & 126 & 164 & 229 & 180 \\
\hline Venezuela & 836 & 985 & 2183 & 5536 & 4495 & 3187 & 4110 \\
\hline Total & 14249 & 27789 & 41301 & 61125 & 66025 & 85571 & 67191 \\
\hline
\end{tabular}

Fonte: Cepal, 1999.

*Média anual.

**Estimativa. 
Nos anos 90, a América Latina alcançou grande sucesso na atração de novos investimentos. Apenas no biênio 1997-1998, a média anual de entrada foi de cerca de US\$ 70 bilhões, enquanto que a média anual anterior à década de 90 nunca ultrapassara US\$ 10 bilhões. Os investimentos diretos estrangeiros saltaram de $1 \%$ para $4 \%$ do PIB entre $1980 \mathrm{e}$ 1998 (cf. Mortimore, 2000).

A visão dominante no campo da teoria econômica neo-clássica sugere que a integração crescente das economias em desenvolvimento na economia mundial traz sempre mais vantagens do que desvantagens. Considera-se que as variações positivas no fluxo de investimentos externos são capazes de deflagrar processos de reestruturação competitiva com forte incidência na produtividade geral e na produtividade do trabalho nos países hospedeiros. Consequentemente, as economias mais abertas são vistas e entendidas como mais capazes de crescer do que as economias fechadas, assim como estariam mais habilitadas a se beneficiar de technological spillovers (processo de transbordamento e de expansão tecnológica) (cf. Edwards, 1995; Frankel \& Romer, 1999).

Essas análises conectadas com a visão dominante dos anos 90 receberam substancial reforço empírico com a pesquisa realizada por Sachs e Warner, em famoso ensaio de 1995. Esses autores procuraram estabelecer relações entre os índices de crescimento dos países pesquisados (cerca de 60) e o grau de abertura de suas economias. Para eles, os indicadores das economias fechadas enfrentavam maior dificuldade para se nivelar num mesmo patamar. Por isso, concluíram: "Economias abertas são capazes de provocar uma convergência de renda mais rapidamente do que as economias fechadas, uma vez que a mobilidade internacional de capital e tecnologia pode acelerar a transição para uma condição mais estável e equilibrada da renda" (Sachs \& Warner, 1995).

Os estudos de Sachs e Warner estimularam a formulação de políticas públicas em muitos países em desenvolvimento, todas baseadas na rápida desregulamentação e abertura de suas economias. A mecânica dessas sugestões residia na busca da recuperação da eficiência econômica-perdida com o envelhecimento das políticas protecionistas - e, dessa forma, do crescimento sustentado, deixando para os mercados, mais do que para os governos, a definição da melhor alocação dos recursos. Sem os constrangimentos estatais do passado, a eficiência desse processo de investimento estaria garantida pela decisão autônoma dos agentes econômicos individuais, sendo que estaria reservado ao setor público a salvaguarda das regras do novo jogo, ou seja, a manutenção da estabilidade macroeconômica.

Com o aprofundamento do debate e as experiências asiáticas dos Tigres, novas pesquisas trataram de questionar essas orientações, pois os resultados alcançados por essas economias intensamente dirigidas pelo Estado não eram compatíveis com as orientações de inspiração neo-clás- 
sica (cf. Amsden, 2001; Wade, 1990; Lall, 1994; e Singh, 1994). Os países asiáticos atualizaram a discussão sobre as políticas industriais, sugerindo que políticas seletivas orientadas para a produção e integradas a projetos de conjunto de desenvolvimento poderiam ser utilizadas com muita eficiência, tornando-se peça-chave nos processos de capacitação tecnológica e no esforço exportador.

O desenvolvimento do Japão, da Coréia, de Taiwan, de Singapura e de outros ajudou a mostrar que é falso o pressuposto da disponibilidade tecnológica no mundo atual. Não somente esta continua protegida pelos grandes centros e corporações, como também não pode ser transferida de um país para outros como se fosse uma simples commodity. Seu uso exige um investimento permanente em novas habilidades e sistemas relacionais que exigem a definição de políticas específicas para funcionar. A questão-chave nessa área diz respeito aos sistemas de aprendizagem ou, como disse Joseph Stiglitz, um processo contínuo de "learning to learn". Longe de ser uma operação de fácil consecução, o aprendizado tecnológico é uma operação que enfrenta enormes obstáculos nos países atrasados, não somente pela escassez de recursos como também pelas dificuldades de seu fluxo em meio ao fogo cruzado da competição internacional. Uma das grandes lições do crescimento acelerado na Ásia foi a indicação de que o controle de novas tecnologias só poderá ser cumulativo e sistemático se sustentado por políticas públicas consistentes, como experiências da FAPESP na área da biotecnologia e genética têm comprovado.

Quando observamos o desempenho dos países da América Latina nos anos 90 - e nos lembramos dos saltos econômicos e tecnológicos dos países asiáticos, somos imediatamente levados a questionar as premissas e as políticas que as agências internacionais sugeriram intensivamente.

\section{América Latina - Indicadores Macroeconômicos}

\begin{tabular}{lcccccccccc} 
& \multicolumn{1}{c}{$\%$} \\
& $1985 / 90$ & 1990 & 1991 & 1992 & 1993 & 1994 & 1995 & 1996 & 1997 \\
& 1.6 & -0.2 & 3.9 & 3.2 & 4.1 & 5.6 & 0.4 & 3.5 & 5.3 \\
PIB & 5.2 & 6.0 & 3.6 & 7.1 & 11.7 & 10.7 & 10.4 & 11.3 & 13.2 \\
Exportação & 17.2 & 18.2 & n.a. & 19.1 & 19.4 & 20.5 & 19.1 & 19.3 & 21.2 \\
$\begin{array}{l}\text { Formação } \\
\text { de Capital }\end{array}$ & & & & & & & & & \\
Inflação & 686.5 & 1188.8 & 199.3 & 426.7 & 890.2 & 337.6 & 25.8 & 18.5 & 10.6
\end{tabular}


A partir dos principais indicadores, podemos destacar alguns resultados positivos: (1) drástica redução da inflação, que caiu de três dígitos no final dos anos 80 para algo em torno de 10\% em 1997; (2) crescimento, ainda que moderado, do volume de exportações; e (3) explosão do fluxo de capital externo (tanto em portfólio quanto em IDE), cujos efeitos ainda estão sendo analisados. Ao mesmo tempo, no mesmo período, pudemos registrar resultados profundamente desanimadores. Fundamentalmente, um baixo crescimento do PIB e do emprego, uma performance pobre da produtividade, uma tímida recuperação da relação $\mathrm{PIB} /$ investimento produtivo e a persistência de um dos piores indicadores de distribuição de renda do mundo, tanto individual quanto regional. E do ponto de vista macroeconômico, terreno por excelência de responsabilidade governamental, a vulnerabilidade das economias tornou-se quase um pesadelo, ilustrado pelas sucessivas crises do México, do Brasil e da Argentina, dada a enorme dependência de capitais e investimentos externos.

Se olharmos de um modo mais apurado para esses novos investimentos, especialmente os diretamente alocados em ativos produtivos (Investimento Direto Externo, IDE), podemos encontrar outras realidades que os macronúmeros quase sempre conseguem esconder.

Utilizando os modelos propostos por Dunning (1993) para classificar os investimentos diretos na América Latina, vamos concluir que o continente atraiu basicamente "um investimento reativo, de segundo ou terceiro nível, oriundo de corporações transnacionais que procuram incrementar a eficiência de seus sistemas produtivos regionais, e não aquele tipo de investimento, o de primeiro nível, capaz de conquistar os mercados", como disse Mortimore (Mortimore, 2000 p. 47). Na verdade, com exceção do México, os países da América Latina estão recebendo apenas gotas dos investimentos produtivos realmente capazes de alterar e dinamizar tanto o acesso aos mercados internacionais quanto ao controle e geração de tecnologias de ponta.

Ainda que os diversos países do continente tenham exibido performances diferenciadas, os defensores desse novo paradigma reconhecem que os resultados não foram tão positivos quanto o esperado. Nesse sentido, o Banco Mundial, por exemplo, procura hoje apresentar algumas explicações para o tímido desempenho da economia na década, que poderiam ser agrupadas da seguinte forma: (1) os documentos do banco enfatizam a variável tempo. Ou seja, ainda seria cedo para um diagnóstico definitivo, pois mudanças profundas no continente ainda estão ocorrendo e deverão mostrar bons resultados brevemente; (2) os dados agregados podem não estar alcançando as mudanças reais que ocorreram no nível da microeconomia. Ou seja, a realidade seria melhor do que os indicadores; e (3) os países latino-americanos não teriam realizado ou completado as reformas necessárias. 


\section{Investimentos Estrangeiros na América Latina - década de 90}

\begin{tabular}{|c|c|c|}
\hline Setor & Primário & Indústria \\
\hline $\begin{array}{l}\text { Alvo nos } \\
\text { recursos } \\
\text { naturais }\end{array}$ & $\begin{array}{l}\text { Petróleo, Gás: } \\
\text { Venezuela, } \\
\text { Colômbia, } \\
\text { Argentina; } \\
\text { Minerais: Chile, } \\
\text { Argentina, Peru. }\end{array}$ & \\
\hline $\begin{array}{l}\text { Foco nos } \\
\text { mercados } \\
\text { domésticos } \\
\text { (indústria) }\end{array}$ & & $\begin{array}{l}\text { Automotivo: } \\
\text { Mercosul; } \\
\text { Químico: } \\
\text { Brasil; } \\
\text { Agro-indústria: } \\
\text { Brasil, México, } \\
\text { Argentina. }\end{array}$ \\
\hline $\begin{array}{l}\text { Foco nos } \\
\text { mercados } \\
\text { domésticos } \\
\text { (serviços) }\end{array}$ & & \\
\hline $\begin{array}{l}\text { Foco na } \\
\text { eficiência }\end{array}$ & & $\begin{array}{l}\text { Autoveículos: } \\
\text { México; } \\
\text { Eletrônico: } \\
\text { México, } \\
\text { Caribe; } \\
\text { Vestuário: } \\
\text { Caribe, } \\
\text { México. }\end{array}$ \\
\hline $\begin{array}{l}\text { Foco em } \\
\text { vantagens } \\
\text { estratégicas } \\
\text { especialmente } \\
\text { nova } \\
\text { tecnologia }\end{array}$ & & \\
\hline
\end{tabular}

Serviços

Finanças: Brasil, México, Chile, Argentina;

Telecomunicações:

Brasil, Argentina,

Chile, Peru;

Energia elétrica:

Colômbia, Brasil,

Argentina, América

Central;

Gás (Distribuição):

Argentina, Brasil,

Chile, Colômbia.

Para a tipologia, cf. Dunning, 1993.

Para a sua aplicação, cf. Mortimore, 2000 e Cepal, 1999. 
Como um dos maiores entusiastas desse novo modelo, o Banco Mundial tem orientado seu debate com os policy makers, ora no sentido de detectar imperfeições na execução das reformas, ora no sentido de descobrir ou engrossar a lista das novas reformas que seriam necessárias. Foi dessa forma que a lista de mudanças institucionais sugeridas no início dos anos 90 nunca parou de crescer.

\section{Recomendações do Banco Mundial}

\section{Início dos anos 90}

01. Liberalização comercial

02. Abertura para os investimentos externos

03. Disciplina fiscal

04. Reorientação dos gastos públicos

05. Privatização intensiva

06. Taxa de câmbio competitiva e unificada

07. Liberalização financeira

08. Reforma fiscal e tributária

09. Desregulação da economia

10. Garantias ao direito de propriedade

\section{Lista expandida}

11. Novas instituições reguladoras

12. Reforma política

13. Fim da corrupção

14. Redes de proteção social

15. Flexibilização do mercado de trabalho

16. Aceitação das regras da OMC

17. Reforma do sistema financeiro

18. Diminuição da pobreza

19. Abertura (prudente) das contas de capital

20. Regime de câmbio unificado

Mais importante do que a ampliação desmesurada da lista de reformas, gostaríamos de realçar o destaque dado pelo Banco Mundial à importância do aprimoramento institucional dos países latino-americanos. Ainda que expressa de modo genérico, essa preocupação é fundamental, uma vez que o desamparo institucional é grande na região. Mas a ênfase foi tardia, pois esse tipo de recomendação teria sido muito mais eficaz no início do processo de reformas quando, de fato, cedeu lugar às pressões pela rápida abertura da economia, pela estabilização da moeda e pelo programa de privatizações. A oportunidade e o timing da implementação de reformas institucionais possuem enorme significado. Neste caso, o tempo é variável-chave, pois se tratava da abertura de um 
processo necessariamente turbulento, voltado para a demolição de estruturas políticas e econômicas vigentes há décadas.

A tensão que tomou conta das sociedades latino-americanas deveu-se muito mais ao seu despreparo para a concepção e negociação de novas instituições, em meio às bruscas alterações do novo ambiente liberalizado de suas economias, do que à a vontade governamental de realizá-las. Até hoje, a carência de instituições voltadas para incentivar o fluxo exportador, com raras exceções, é ilustrativa dessa hesitação. As pressões dos novos credores e das agências internacionais e a reação claudicante dos governos retiraram das sociedades o tempo necessário para o amadurecimento das reformas, tempo para a persuasão de grupos sociais, para a busca da acomodação ou eqüacionamento dos conflitos. Em outras palavras, diante do açodamento, da sucessão de desencontros e do desencanto com a lenta colheita de resultados positivos, a América Latina continuou gesticulando como um relojoeiro cego que teve o seu tempo seqüiestrado.

A discussão de fundo que precisa ser atualizada diz respeito ao modo como o novo modelo econômico que impregnou a América Latina nos últimos anos negligenciou as dimensões da política, da produção e do lugar do Estado no desenvolvimento. A esterilização da política, o deslocamento da produção e a conseqüente prevalência dos mercados, assim como a contenção e drenagem do poder estruturante do Estado, deram suporte para uma crítica arrasadora do desenvolvimentismo, sem que fosse criado e implantado um novo sistema substitutivo, compensador e mais eficiente.

A tibieza do necessário diálogo; a negociação e a articulação dos agentes econômicos e sociais; a negativa de implantação de um vasto programa de capacitação tecnológica; a ausência de suporte para a dinamização da capacidade gerencial e empreendedora das empresas minaram os processos de aprendizagem e de aquisição de novos conhecimentos e tecnologia. Os governos, praticamente, contentaram-se com a administração da macroeconomia, sendo que o ajuste fiscal e a flexibilização do comércio internacional foram transformados em palavras quase mágicas na boca de seus porta-vozes.

Tendo como ponto de partida um diagnóstico equivocado - o tamanho dos mercados seria o principal obstáculo ao desenvolvimento dos países -, a atuação governamental seria levada a desprezar as questões relacionadas aos poderes assimétricos que regem as nações, o comércio, os mercados, o acesso à tecnologia de ponta, as transnacionais, a competição oligopolística e, essencialmente, a natureza do aprendizado em todo processo de renovação industrial e desenvolvimento. Em outras palavras, sem o enfrentamento das questões relacionadas ao poder diferenciado existente nas sociedades, a atividade política só poderia sobreviver sem a menor nobreza, e a atividade econômica travestida de isentos 
contornos técno-científicos. Não foi à toa que o novo paradigma econômico reduziu as reformas necessárias à retomada do desenvolvimento dos países a um guia de condutas sobre como desregulamentar, como liberalizar e privatizar, banindo ou pasteurizando o debate sobre um novo compromisso pela produção, capaz de ocupar o vácuo do desenvolvimentismo e a passividade de corte liberal dos anos 90.

Não haverá discurso ou decreto capaz de substituir a necessária negociação e construção desse novo compromisso nas sociedades latinoamericanas. Diferentemente dos anos 50, quando a industrialização pesada predominou, as políticas industriais de hoje só terão eficácia se apoiadas em sistemas locais e regionais voltados para a inovação e o aprendizado, aptos a difundir as novas tecnologias e a promover, simultaneamente, a especialização produtiva. As iniciativas voltadas para facilitar o intercâmbio entre empresas e instituições, públicas e privadas, só poderão mostrar-se eficientes se integradas aos centros de pesquisa e às universidades por meio de políticas seletivas estimuladas pelo governo central, orientadas para a geração de conhecimento de longa duração.

O paradigma latino-americano dos anos 90 foi desenvolvido sem respeitar a história dos países do continente, ou dando relevo a uma história tendenciosa dos países em desenvolvimento, seja pela tábula rasa efetivada da experiência desenvolvimentista, seja pela estranhamento em relação aos êxitos alcançados por vários países asiáticos.

Explicar porque alguns desses países se industrializaram mais rapidamente do que outros e porque as taxas de crescimento divergiram no tempo são questões extremamente atuais e desafiadoras.

As respostas mais instigantes são as que procuram olhar as interações entre as trocas e o mundo da produção, de modo a poder delinear os contornos dos novos sistemas de conhecimento e aprendizagem, capazes de reorientar e revitalizar os velhos sistemas nacionais de produção construídos com base no protecionismo anterior. Desenvolver essa abordagem significa elaborar e selecionar novas estratégias de desenvolvimento, de modo a responder às questões sobre o tipo de tecnologia e de industrialização, assim como a qualidade das instituições de apoio, regulação e fomento que os países realmente precisam. É nesse sentido que afirmamos que as mudanças tarifárias e a abertura comercial formam apenas uma pequena parte de um processo muito maior. $\mathrm{O}$ grande desafio é a promoção de profundas transformações nos padrões de comportamento, na relação do governo com o setor privado, com a sociedade e com o restante do mundo.

Se olharmos para os Tigres asiáticos, ou para a China ou para a Índia, veremos que esses países foram beneficiados por sua progressiva integração com a economia mundial. Mas todos os seus passos foram orientados por um conjunto de estratégias de desenvolvimento. Combinaram seu esforço exportador com políticas de proteção de sua econo- 
mia, como as altas tarifas, exportações subsidiadas, exigência de conteúdo nacional nos produtos das multinacionais, restrição ao fluxo de capitais. Em todos esses países, a liberalização da economia foi um processo lento e gradual, desenvolvido ao longo do tempo. E uma abertura mais ampla somente foi operacionalizada quando suas economias estavam nos trilhos, preparadas para crescer. Em outras palavras, abertura comercial, liberalização, desregulamentação não podem substituir as estratégias de desenvolvimento, o mais efetivo meio de se alcançar uma integração dinâmica e virtuosa para o país com a economia mundial.

O novo modelo latino-americano operou pelo reverso: os países liberalizaram seu comércio e desregulamentaram os fluxos de capital como se isso fosse suficiente para deflagrar processos de crescimento; ignoraram o fato que a integração com a economia mundial, diferentemente da regulação tarifária, não pode ser controlada diretamente pelos governantes e autoridades econômicas.

Se há lições a aprender, estão indicando que os países em desenvolvimento, antes de mais nada, precisam definir quais políticas, quais instituições e quais forças sociais podem sustentar suas estratégias. Não se trata de afirmar que o protecionismo é melhor do que a abertura ou a desregulamentação. Trata-se de compreender que a liberalização em si não é garantia de eficácia, ainda que tenha sido, nos últimos anos, ostensivamente sobrevalorizada. Os países que alcançaram relativo sucesso em promover um crescimento de longo prazo combinaram as oportunidades oferecidas pelos mercados mundiais (basicamente através da tecnologia e de capitais) com estratégias que tornaram efetivas (seja criando, refazendo ou adaptando) as instituições domésticas e que se debruçaram sobre o setor da produção e do trabalho.

Sociedades com profundas clivagens sociais e frágeis instituições, como o Brasil, vivem enormes dificuldades para governar seus conflitos e resistir aos choques externos e às oscilações da economia internacional. Quais instituições são necessárias? Quais as prioridades? Esse é o debate de fundo, que exige democracia para se realizar e mobilização social para superar a cegueira voluntária da liberalização dos anos 90.

O modo como procurei trabalhar essa minha avaliação só adquire sentido se baseado no pressuposto da recuperação da política como suporte da cidadania, da solidariedade e das sociedades. Nesse ano eleitoral, ousaria sugerir que algumas dessas questões pudessem informar a fala dos candidatos. Sem muita esperança (como sugeriu o poeta), pois as pesquisas de opinião sempre acabam indicando outros caminhos para o encontro do eleitor. Espero, porém, sinceramente, que a discussão volte a esse trilho, do qual nunca deveria ter saído. Pois se um novo compromisso não puder ser costurado no Brasil, a promessa da anunciada desmontagem da herança varguista continuará como um espectro a nos atormentar. E isso num Brasil agora sem passado, pois o desenvolvi- 
mentismo não voltará. Mas também com um futuro que teima em não se realizar.

Recebido para publicação em março/2002

KEYWORDS:

Latin America, developing countries, technology, free trade, strategies of development.
ARBIX, Glauco. From the blind liberalization of the 90's to the strategic building of development. Tempo Social, Rev. Sociol. USP, S. Paulo, 14(1): 1-18, May 2002 .

ABSTRACT: This paper was presented as the inaugural class for the Social Sciences Course at USP, on the 6th of March of 2002. Global economy has been undergoing a number of sweeping changes that have altered the methods, the organization of the production of goods and services, politics and institutions all over the world. These changes have been more marked in countries where State policies exert strict control over the economy and social life. In Latin America, these changes guided the implementation of a new economic policy model, as a means to overcome rising inflation, balance-of-payment deficits, the international debt load, inefficiency and the lack of international competitiveness, all of which had supposedly arisen as the product of traditional developmental policies. However, this new model operates with a devious interpretation of the history of developing countries, by dismissing or not taking into account the fact that countries such as Brazil, Argentina and Mexico, alongside other Asian countries, experienced a faster growth-rate than the USA, England, Germany, France and Canada. The real challenge for those countries lies in the elaboration of strategies for development, including the quality of aspired industrialization, technology, institutions and politics.

\section{REFERÊNCIAS BIBLIOGRÁFICAS}

AMSDEn, Alice. (2001) The rise of the rest: Late industrialization outside the north atlantic region. Oxford, Oxford University Press.

Bourdieu, Pierre \& Wacquant, Loïc. (2000) La nouvelle vulgate planétaire. In: Le Monde Diplomatique, p. 6-7, maio.

CEPAL. (1999) Statistical yearbook for Latin America and the Caribbean.

CHANG, Ha-Joon. (2001) Infant industry promotion in historical perspective: a rope to hang oneself or a ladder to climb with? Cepal.

DunNING, John. (1993) The theory of transnational corporations. London, Routledge (United Nations Library on Transnational Corporations, v. 1). 
EDWARds, Sebastian. (1995) Crisis and adjustment in Latin America: from despair to hope. Oxford, Oxford University Press.

Frankel, Jeffrey \& Romer, David. (1999) Does trade cause growth? American Economic Review, 89(3): 379-399, june.

HABERMAS, Jurgen. (1971) The scientization of politics and public opinion. In: . Toward a rational society. Londres, Heinemann Educational Books.

LALl, Sanjaya. (1994) The East Asian miracle study: does the bell toll for industrial strategy? World Development, 22(4): 645-654.

Mortimore, Michael. (2000) Corporate strategies for FDI in the context of Latin America's new economic model. World Development, 28(9): 1611-1626.

OcAmpo, José. (2001) Retomar la agenda del desarrollo. Cepal.

RodrIGUEZ, Francisco e RoDRIK, Dani. (2000) Trade policy and economic growth: a skepetic's guide to the cross-national literature. Cambridge, NBER.

SACHS, Jeffrey \& WARnER, Andrew. (1995) Economic reform and the process of global integration. Brookings Papers on Economic Activity, 1: 1-118.

SingH, Ajit. (1994) Openness and the market friendly approach to development: learning the right lessons from development experience. World Development, 22(12): 1811-1824.

TAYLOR, Lance. (1994) Hirschman's strategy at thirty-five. In: RoDWIN, Lloyd \& Schön, Donald (eds.). Rethinking the development experience. Washington, The Brookings Institution.

UNCTAD. (2000) World investiment report.

Wade, Robert. (1990) Governing the market. Princeton, Princeton University Press. 